\title{
Development and Validation of Food Frequency Questionnaire to Assess Calcium Intake in Postmenopausal Vietnamese Women
}

\author{
Nguyen Cong KHAN ${ }^{1}$, Le Bach MAI ${ }^{1}$, Vu Thi Thu HIEN ${ }^{1,2}$, Nguyen Thi LAM ${ }^{1}$, Vu Quynh HoA ${ }^{1}$, \\ Tuan Mai PHUONG ${ }^{1}$, Bui Thi Nhung ${ }^{1,3}$, Masayo NAKAMORI ${ }^{2}$, Yukue SHIMIZU ${ }^{2}$ \\ and Shigeru YAMAMOTO ${ }^{2, *}$ \\ ${ }^{1}$ National Institute of Nutrition, Vietnam \\ ${ }^{2}$ Department of International Nutrition, Ochanomizu University Graduate School of Humanities and Sciences, \\ Tokyo 112-8610, Japan \\ ${ }^{3}$ Department of International Public Health Nutrition, Tokushima University Graduate School of \\ Health Biosciences, Tokushima 770-8503, Japan
}

(Received June 18, 2007)

\begin{abstract}
Summary This study was done to develop a Food Frequency Questionnaire (FFQ) for assessing calcium intake in Vietnamese based on data from the National Nutrition Survey in 2000. From the data, a total of 36 calcium-rich food items were selected for the FFQ by ranking food items according to their contribution to the population intake of nutrients. The FFQ was validated in 140 postmenopausal women by comparing estimates of calcium intake from the FFQ with those from multi-pass $24 \mathrm{~h}$ recalls. The results showed that the Pearson correlation coefficient between the 2 methods was $0.84(p<0.001)$, and that the weighted kappa value was 0.44 . Cross-classification analysis indicated that $82.1 \%$ of subjects were classified into the same or adjacent quartile by both methods. No subject was grossly misclassified by the FFQ. There is no significant difference of calcium intake between the 2 methods (by paired $t$ test, $p>0.05$ ). A reproducibility study also presented good correlation between 2 administrations of the FFQ, with Pearson correlation coefficient being 0.93 $(p<0.001)$ and weighted kappa value being 0.67. In conclusion, this FFQ is useful and reliable for estimating calcium intake in population-based epidemiological studies in postmenopausal Vietnamese women.
\end{abstract}

Key Words Food Frequency Questionnaire (FFQ), calcium, validation, postmenopausal Vietnamese women

In recent years, considerable evidence has emerged with respect to the effects of dietary calcium on bone health (1). There is increasing emphasis on the need for lifelong adequate calcium intake in both males and females (2). Optimal calcium intake is necessary not only for maximization of peak bone mass during youth, but also for minimization of bone loss later in life (3). Low calcium intake has been considered as a risk factor for osteoporosis $(4,5)$. Thus, identifying suitable methods to assess calcium intake of people has been highlighted. Consequently, there is a need for developing cost-effective methods of estimating calcium intake that is practical for large-scale epidemiologic studies on osteoporosis $(3,6)$. Of methods that could be used for the dietary assessment, the Food Frequency Questionnaire (FFQ) appears to be simple, reliable, and quite convenient for assessing calcium intake. It has been designed and validated for use in some populations (715).

In Vietnam, the prevalence of osteoporosis in women aged 20 and above was $9 \%$, relatively high compared to surrounding countries (16). To date, there was a FFQ

*To whom correspondence should be addressed.

E-mail: yamamoto.shigeru@ocha.ac.jp developed and validated in Vietnamese for assessing various nutrients, including calcium, but it comprises more than 100 food items (17). Hence, a simpler FFQ for estimating the calcium intake among Vietnamese people is necessary for epidemiological studies on osteoporosis. Thus, the purpose of this study was to develop and validate the first simple FFQ to assess calcium intake in postmenopausal Vietnamese women, the population at high risk for osteoporosis.

\section{MATERIALS AND METHODS}

Development of FFQ. The calcium-specific FFQ used in the present study was developed on the basis of data from the Vietnamese National Nutrition Survey in 2000 , in which calcium intake was assessed from $24 \mathrm{~h}$ recall combined with a weighed record method. In the survey, investigators weighed and recorded all food items consumed, measuring them as raw materials before cooking. In some cases where foods could not be weighed before cooking, the weights of raw materials were calculated by both investigators and subjects, using a recall method and food samples (18). Dietary intake of 4,080 adults who were living in the Red River Delta collected in the National Nutrition Survey was used as data for developing the FFQ. A total of 231 dif- 
ferent food codes were counted from such people. All food codes were grouped into 146 conceptually similar food items. The percent of calcium content which was contributed by each food item was determined, and foods were ranked in order of their contribution. The cumulative percentage contribution was computed. Using the method of Block et al. (19), the rank of 36 food items contributing cumulatively to $90 \%$ of the total calcium intake of 4,080 subjects was drawn to develop the food list for the new FFQ.

Based also on the dietary intake of 4,080 such people, the average portion size was estimated for each food item in the FFQ. The actual portion size will be asked, whether the size was half as much, the same, 1.5 times larger, or twice the average portion size. We use a photograph album of common foods and some kinds of spoon and bowls for the FFQ interview to improve the accuracy of a subject's recall. Food frequency in the FFQ was classified into 10 categories: never, less than once per month, 1-3 times per month, 1-2 times per week, 3-4 times per week, 5-6 times per week, once per day, 2-3 times per day, 4-5 times per day, and more than 6 times per day.

Calcium intake from each food item was estimated by the following formula:

\section{Calcium intake}

$=$ portion size in grams $\times$ reported consumption frequency (converted to times per day) $\times$ calcium content per gram.

The total calcium intake of each subject was the sum of calcium intake from all food items in the FFQ.

Test-retest reliability and validation study. The study was approved by the Research and Ethical Committee of the Vietnamese National Institute of Nutrition, and was conducted in Hai Duong province in April 2004.

A total of 140 postmenopausal women aged from 50 to $70 \mathrm{y}$ and free of a history of fracture or diseases affecting bone metabolism were selected and invited to participate in the study.

The test-retest reliability of the FFQ was assessed by comparing the results obtained from the first testing of the FFQ (FFQ1) with those obtained from the second testing of the FFQ (FFQ2) in the same subjects $10 \mathrm{~d}$ later.

Calcium intake from the FFQ was validated by referring to that from $24 \mathrm{~h}$ recalls as standard value (20). Three non-consecutive $24 \mathrm{~h}$ recalls were conducted during the period between first and second administration of the FFQ in the same subjects, covering two weekdays and one weekend day. Participants were requested to recall the type and amount of any food consumed during the previous day in chronological order, i.e. from the time they woke up in the morning to the same time the following day. To improve the accuracy of food descriptions, a full-size photograph album of common food and standard household measures (bowls, cups, spoons) were used during interviews to define appropriate amounts. The mean values of calcium intake from three $24 \mathrm{~h}$ recalls were used as reference values to compare with results from the FFQ.
All subjects gave informed consent before participating in the study. They were asked to maintain their usual diets during the study period.

Statistical analysis. Calcium intake was computed separately for the FFQ and $24 \mathrm{~h}$ recalls, and only then were comparisons done. The database for the calcium content estimate was represented by the Vietnamese food composition table (21).

Calcium intake by both the FFQ and the $24 \mathrm{~h}$ recalls were normally distributed. Pearson's correlation analysis was performed to compare the calcium intake between FFQ1 versus $24 \mathrm{~h}$ recalls, and FFQ1 versus FFQ2. Student's paired $t$ test was also used to compare mean calcium intake between the 2 methods.

Cross-classification analysis was carried out to identify the proportion of subjects correctly classified (into the same or adjacent quartiles) and grossly misclassified

Table 1. Contribution of 36 food items included in the FFQ to calcium intake. (Data was drawn from the National Nutrition Survey in 2000)

\begin{tabular}{|c|c|c|}
\hline Food item & $\begin{array}{c}\text { Contribution } \\
(\%)\end{array}$ & $\begin{array}{c}\text { Cumulative } \\
\text { contribution } \\
(\%)\end{array}$ \\
\hline 1. Small crab & 33.80 & 33.80 \\
\hline 2. Ordinary polished rice & 16.18 & 49.98 \\
\hline 3. Water spinach & 12.99 & 62.98 \\
\hline 4. Small shrimp & 4.27 & 67.25 \\
\hline 5. Fish sauce & 4.20 & 71.45 \\
\hline 6. Sauropus & 3.53 & 74.98 \\
\hline 7. Mussel & 2.23 & 77.21 \\
\hline 8. Helix & 1.66 & 78.87 \\
\hline 9. Jute potherb & 1.60 & 80.47 \\
\hline 10. Vinespinach & 1.12 & 81.59 \\
\hline 11. Amaranth & 1.01 & 82.60 \\
\hline 12. Major carb & 0.86 & 83.46 \\
\hline 13. Soy milk & 0.84 & 84.30 \\
\hline 14. Tofu & 0.78 & 85.08 \\
\hline 15. Sesame & 0.69 & 85.77 \\
\hline 16. Peanut & 0.42 & 86.19 \\
\hline 17. Rice noodle & 0.42 & 86.61 \\
\hline 18. Clam & 0.38 & 86.99 \\
\hline 19. Duck egg & 0.37 & 87.36 \\
\hline 20. Pork medium fat & 0.33 & 87.69 \\
\hline 21. Mustard greens & 0.31 & 88.00 \\
\hline 22. Glutinous rice & 0.26 & 88.25 \\
\hline 23. Vermicelli & 0.25 & 88.50 \\
\hline 24. Sugar apple & 0.24 & 88.75 \\
\hline 25. Cow milk & 0.21 & 88.96 \\
\hline 26. Milk powder & 0.17 & 89.13 \\
\hline 27. Chicken egg & 0.15 & 89.27 \\
\hline 28. Scad & 0.15 & 89.42 \\
\hline 29. Orange & 0.14 & 89.55 \\
\hline 30. Bread & 0.11 & 89.67 \\
\hline 31. Pork lean & 0.09 & 89.75 \\
\hline 32. Tamarind leaves & 0.08 & 89.83 \\
\hline 33. Pork leg & 0.07 & 89.90 \\
\hline 34. Chicken meat & 0.06 & 89.96 \\
\hline 35. Beef & 0.02 & 89.98 \\
\hline 36. Pork ribs & 0.02 & 90.01 \\
\hline
\end{tabular}


Table 2. Pearson correlation coefficient, percentage of subjects classified into the same and opposite quartiles of calcium intake from FFQs and $24 \mathrm{~h}$ recalls.

\begin{tabular}{|c|c|c|c|c|}
\hline & \multirow{2}{*}{$\begin{array}{c}\text { Pearson } \\
\text { correlation } \\
\text { coefficient }\end{array}$} & \multicolumn{2}{|c|}{ Percentage of subjects classified in } & \multirow{2}{*}{$\mathrm{Kw}$} \\
\hline & & Same or adjacent quartiles & Opposite quartile & \\
\hline FFQ1 versus $24 \mathrm{~h}$ recalls & 0.84 & 82.1 & 0.0 & 0.44 \\
\hline FFQ1 versus FFQ2 & 0.93 & 85.7 & 0.0 & 0.67 \\
\hline
\end{tabular}

(lowest quartile for one method and highest quartile for the other) by the FFQ. Quartiles were determined from each method's own calcium distribution. A weighted kappa statistic was used to evaluate how well the FFQ method could categorize individuals into quartiles of calcium distribution when compared with the $24 \mathrm{~h}$ recalls categorization (22).

All statistical analyses were performed with the SPSS software for Windows version 10.0 (SPSS, Chicago, USA).

\section{RESULTS}

The rank of food items drawn from the data of the Vietnamese National Nutrition Survey in 2000 for developing the food list in the FFQ is shown in Table 1.

of the food items, small crabs account for a considerable percentage of contribution (33.8\%) to the calcium intake of the population in the Red River Delta. Rice, a main part of Vietnamese meals, contributed $16.1 \%$. It is worth noting that dairy products (cow milk and milk powder) contributed only $0.38 \%$. In the validation study, the mean calcium intake obtained from the FFQ (FFQ1) and $24 \mathrm{~h}$ recalls were $345 \pm 116 \mathrm{mg} / \mathrm{d}$ and $358 \pm 99 \mathrm{mg} / \mathrm{d}$, respectively. There is no significant difference between calcium intakes derived from the two methods ( $p>0.05$ by Student's paired $t$ test). As shown in Table 2, the Pearson correlation coefficient was 0.84 $(p<0.001), 82.1 \%$ subjects were correctly classified into the same or adjacent quartiles, no subject was grossly misclassified by FFQ, and the weighted kappa value was 0.44 .

The test-retest reliability study done to compare calcium intake from FFQ2 versus FFQ1 indicated that the Pearson correlation coefficient was $0.93(p<0.001)$, $85.7 \%$ subjects were correctly classified into the same or adjacent quartiles, no subject was grossly misclassified by FFQ, and the weighted kappa value was 0.67 (Table 2).

\section{DISCUSSION}

Calcium intake has a considerable influence on skeletal health (1), and its adequate intake from food is of major importance for preventing osteoporosis and reducing fracture risk (2). Because osteoporosis has serious consequences and affects the individual as well as the family and the community (23), a recommendation was made for developing cost-effective methods to identify those with insufficient calcium intake (3). To date, the FFQ method has been considered as the most convenient and feasible one for this purpose and it has been validated for use in many populations $(7,15)$.

Taking all this information into consideration, and because Vietnamese are facing a relatively high prevalence of osteoporosis compared to nearby countries (16), we developed and validated the FFQ for assessing calcium intake for postmenopausal Vietnamese women in epidemiological studies.

Our findings indicated that total of 36 food items can reach a $90 \%$ cumulative contribution of calcium intake of the population living in the Red River Delta. It was similar to the picture of the nearest areas where number of food items was 38 in Southern Vietnam (17) and was 35 in China (24). Differentiating from China (13) where the highest contribution percentages of calcium intake were derived from vegetables $(37.5 \%)$ and dairy products $(17.3 \%)$, our results revealed that small crabs account for a considerable percentage of contribution (33.8\%), followed by rice (16.1\%). This phenomenon is likely due to food sources and eating habits in Vietnamese people. Small crabs contribute a considerable amount of calcium intake, but it is a matter of fact that in our situation nowadays, the small crab is not very often consumed by people (not every day). Ordinary rice is the second contributor to calcium intake but the consumption trend seems to be falling. These indicated that the calcium source from daily food intake is limited and that the increased risk of osteoporosis may be explained by looking at the dietary intake aspect. Intensive nutrition education programs should be implemented in future to improve intake of potential foods which contribute high calcium content at affordable cost such as small crabs and small shrimp. However, in the context of modernizing in Vietnam, cheese and other kinds of dairy products should be added to the FFQ when the dietary pattern changes.

In the validation study, there was no significant difference in the mean calcium intake derived from the FFQ and the reference method ( $p>0.05$ by paired $t$ test). This finding was similar to results from earlier studies (7-11). The Pearson correlation coefficient of 0.84 obtained between the two methods was higher than the range reported previously $(r=0.5-0.8)$ in some studies $(8,11,12,14)$ but lower than that of 0.9 presented in Italian women (10).

The FFQ showed a reasonable ability to classify individuals into quartile of calcium intake, with $82.1 \%$ of subjects being correctly classified into the same or adjacent quartiles, and no subject being grossly misclassified. These results are similar to those assessed from previous FFQs $(12,15,25)$, but are still worse than the 
others where correct classification varies from 92.9 to $95.2 \%(8,26)$. It is worth mentioning that no subject was grossly misclassified by the FFQ, while the proportion was $0-3.4 \%$ in other studies $(8,12,25,26)$. In this study, the weighted kappa value was 0.44 , higher than that in the earlier trial in Southern Vietnam (17).

Our current validation study met levels suggested by Masson et al. (27) that using a correlation coefficient above 0.5 , more than $50 \%$ of subjects correctly classified and less than 10\% subjects grossly misclassified into thirds, and a weighted kappa value above 0.4 are desirable in epidemiological studies.

In the test-retest reliability study, we chose the reasonable time interval of $10 \mathrm{~d}$ to avoid errors from interviewers as well as a subject's recall $(17,28)$. Our study showed a good reproducibility of the FFQ, with the Pearson's correlation coefficient being $0.93(p<0.001)$ and the weighted kappa value being 0.67. Previous publications with the same interval time between 2 administrations of the FFQ revealed lower correlation coefficients which vary from $0.66-0.73(13,17)$ to 0.90 (29).

This study has several potential weaknesses. First, using a $24 \mathrm{~h}$ recall method as reference tool may not be the best for validation purposes. However, multiple $24 \mathrm{~h}$ recalls may provide valid assessments of an individual's usual intake (19). In addition, this method is considered the most suitable to get population means and distribution for subjects with reasonable accuracy, especially when combined with visual aids for estimating portion size (30). Furthermore, our $24 \mathrm{~h}$ recall method was well validated with a weighting method in the same Northern area of Vietnam (31). With our relatively large sample size, we believe that inter-individual variability in daily calcium intake would be decreased. Virtually all previous studies used the $24 \mathrm{~h}$ recall method as a reference tool against calcium FFQs in some population (9, $15,26)$. The second weakness is that we could not validate the new FFQ in 4 seasons. Nevertheless, it has been reported that there was not much seasonal variation occurs in the intake of calcium $(32,33)$. Moreover, in Vietnam, the main sources of calcium rich food, such as small crabs and small shrimp, are available throughout the 4 seasons. Therefore, we believe that our new FFQ can be acceptable for use in all seasons.

In conclusion, this study suggests that the new FFQ can be fruitfully used in epidemiological studies in postmenopausal women in Vietnam due to its validity, reproducibility and feasibility for a large-scale population. It also can be applied to regions surrounding Vietnam which have a similar environment, food sources and food habits, with good consideration of validation and modifying some kind of dairy products, depending on dietary patterns in the regions.

\section{Acknowledgments}

We would like to thank all the subjects for participating, the staff of the Vietnam National Institute of Nutrition for collecting the data, and local officials for collaborating in the study.

\section{REFERENCES}

1) European Commission. 1988. Report on Osteoporosis in the European Community: action for prevention. Office for Official Publications for the European Commission, Luxembourg.

2) Heaney RP. 2002. The importance of calcium intake for lifelong skeletal health. Calcif Tissue Int 70: 70-73.

3) National Institutes of Health. 1994. Optimal calcium intake. NIH Consens Statement 12: 1-31.

4) Lau EMC, Cooper C. 1996. The epidemiology of osteoporosis: The Oriental perspective in a world context. Clin Orthop 323: 65-74.

5) Zhao XH, Chen XS. 1992. Diet and bone density among elderly Chinese. Nutr Rev 50: 395-397.

6) Cummings SR, Block G, McHenry K, Baron RB. 1987. Evaluation of two food frequency methods of measuring dietary calcium intake. Am J Epidemiol 126: 796-802.

7) Blalock SJ, Currey SS, DeVellis RF, Anderson JJB, Gold DT, Dooley MA. 1998. Using a short food frequency questionnaire to estimate dietary calcium consumption: a tool for patient education. Arthr Care Res 11: 479484.

8) Chee WS, Suriah AR, Zaitun Y, Chan SP, Yap SL, Chan YM. 2002. Dietary calcium intake in postmenopausal Malaysian women: comparison between the food frequency questionnaire and three-day food records. Asia Pac J Clin Nutr 11: 142-146.

9) Haines CJ, Chung TK, Leung PC. 1994. Dietary calcium intake in postmenopausal Chinese women. Eur J Clin Nutr 48: 591-594.

10) Montomoli M, Gonnelli S, Giacchi M, Mattei R, Cuda C, Rossi S, Gennari C. 2002. Validation of a food frequency questionnaire for nutritional calcium intake assessment in Italian women. Eur J Clin Nutr 56: 21-30.

11) Taitano RT, Novotny R, Davis JW, Ross PD, Wasnich RD. 1995. Validity of a food frequency questionnaire for estimating calcium intake among Japanese and white women. J Am Diet Assoc 95: 804-806.

12) Wilson P, Horwath C. 1996. Validation of a short food frequency questionnaire for assessment of dietary calcium intake in women. Eur J Clin Nutr 50: 220-228.

13) Xu L, Porteous JE, Phillips MR, Zheng S. 2000. Development and validation of a calcium intake questionnaire for postmenopausal women in China. Ann Epidemiol 10: 169-175.

14) Cummings SR, Block G, McHenry K, Baron RB. 1987. Evaluation of two food frequency methods of measuring dietary calcium intake. Am J Epidemiol 126: 796-802.

15) Magkos F, Manios Y, Babaroutsi E, Sidossis LS. 2006. Development and validation of a food frequency questionnaire for assessing dietary calcium intake in the general population. Osteoporos Int 17: 304-312.

16) Hien VTT, Khan NC, Lam NT, Mai LB, Son LNTD, Nhung BT, Nakamori M, Yamamoto S. 2005. Determining the prevalence of osteoporosis and related factors using quantitative ultrasound in Vietnamese adult women. Am J Epidemiol 161: 824-830.

17) Kusama K, Son LNTD, Hanh TTM, Takahashi K, Hung NTK, Yoshiike N, Yamamoto S. 2005. Reproducibility and validity of a food frequency questionnaire among Vietnamese in Ho Chi Minh city. J Am Coll Nutr 24: 466-473.

18) Vietnam National Institute of Nutrition. 2001. Report on National Food Consumption Survey 2000. Hanoi, 
Vietnam.

19) Block G, Dresser CM, Hartman AM, Carroll MD, Gannon J, Gardner L. 1986. A data-based approach to diet questionnaire design and testing. Am J Epidemiol 124: 453-469.

20) Thompson FE, Byers T. 1994. Dietary assessment resource manual. J Nutr 124: 2245S-2317S.

21) Vietnam National Institute of Nutrition. 2000. Nutritive Composition Table of Vietnamese Foods. Medical Publishing House, Hanoi.

22) Fleiss JL. 1981. Statistical Methods for Rates and Proportions. John Wiley and Sons, New York.

23) National Institutes of Health. 2000. Osteoporosis prevention, diagnosis, and therapy. NIH Consens Statement 17: $1-45$.

24) Zhou ZY, Takezaki T, Mo BQ, Sun HM, Wang WC, Sun LP, Liu SX, Ao L, Cheng GH, Wang YM, Cao J, Tajima K. 2004. Development of a semi quantitative food frequency questionnaire to determine variation in nutrient intakes between urban and rural areas of Chongqing, China. Asia Pac J Clin Nutr 13: 273-283.

25) Taylor RW, Goulding A. 1998. Validation of a short food frequency questionnaire to assess calcium intake in children aged 3 to 6 years. Eur J Clin Nutr 52: 464-465.

26) Green JH, Booth CL, Bunning RL. 2002. Assessment of a rapid method for assessing adequacy of calcium intake. Asia Pac J Clin Nutr 11: 147-150.

27) Masson LF, McNeill G, Tomany JO, Simpson JA, Peace HS, Wei L, Grubb DA, Bolton-Smith C. 2003. Statistical approaches for assessing the relative validity of a foodfrequency questionnaire: use of correlation coefficients and the kappa statistic. Public Health Nutr 6: 313-321.

28) Willett W. 1998. Nutritional Epidemiology, 2nd ed. Oxford University Press, New York.

29) Sato Y, Tamaki J, Kitayama F, Kusaka Y, Kodera Y, Koutani A, Iki M. 2005. Development of a food frequency questionnaire to measure the dietary calcium intake of adult Japanese women. Tohoku J Exp Med 207: 217222.

30) Biro G, Hulshof KF, Ovesen L, Amorim Cruz JA. 2002. Selection of methodology to assess food intake. Eur J Clin Nutr 56: S25-32.

31) Dop MC, Mai LB, Laillo A, Seùneùmaud B, Khan NC, Khoi HH. 2000. Validation of the 24-hour recall against weighing method at household level. Advantage of comparing methods on the same and separate days: a case study from Vietnam. Fourth International Conference on Dietary Assessment Methods, Tucson, USA.

32) Fahey MT, Sasaki S, Kobayashi M, Akabane M, Tsugane S. 2003. Seasonal misclassification error and magnitude of true between-person variation in dietary nutrient intake: a random coefficients analysis and implications for the Japan Public Health Center (JPHC) Cohort Study. Public Health Nutr 6: 385-391.

33) Chen Y, Ahsan H, Parvez F, Howe GR. 2004. Validity of a food frequency questionnaire for a large prospective cohort study in Bangladesh. Br J Nutr 92: 851-859. 
APPENDIX. FFQ to estimate the Ca intake in postmenopausal Vietnamese women.

\begin{tabular}{|c|c|c|c|c|c|c|c|c|c|}
\hline \multirow{2}{*}{ Food item } & \multirow{2}{*}{$\begin{array}{c}\text { Reference } \\
\text { portion size } \\
(\mathrm{g})\end{array}$} & \multicolumn{3}{|c|}{$\begin{array}{l}\text { Actual portion size compared } \\
\text { to reference portion size }\end{array}$} & \multicolumn{4}{|c|}{$\begin{array}{l}\text { Number of portions which subject } \\
\text { consumes in } 1 \text { of } 4 \text { following periods }\end{array}$} & \multirow{2}{*}{ Never eats } \\
\hline & & Smaller & Equal & Bigger & $1 \mathrm{~d}$ & $1 \mathrm{wk}$ & $1 \mathrm{mo}$ & $6 \mathrm{mo}$ & \\
\hline 1. Small crab & 50 & & & & & & & & \\
\hline 2. Ordinary polished rice & 110 & & & & & & & & \\
\hline 3. Water spinach & 65 & & & & & & & & \\
\hline 4. Small shrimp & 50 & & & & & & & & \\
\hline 5. Fish sauce & 5 & & & & & & & & \\
\hline 6. Sauropus & 30 & & & & & & & & \\
\hline 7. Mussel & 80 & & & & & & & & \\
\hline 8. Helix & 75 & & & & & & & & \\
\hline 9. Jute potherb & 20 & & & & & & & & \\
\hline 10. Vinespinach & 30 & & & & & & & & \\
\hline 11. Amaranth & 30 & & & & & & & & \\
\hline 12. Major carb & 100 & & & & & & & & \\
\hline 13. Soy milk & 250 & & & & & & & & \\
\hline 14. Tofu & 50 & & & & & & & & \\
\hline 15. Sesame & 10 & & & & & & & & \\
\hline 16. Peanut & 50 & & & & & & & & \\
\hline 17. Rice noodle & 150 & & & & & & & & \\
\hline 18. Clam & 50 & & & & & & & & \\
\hline 19. Duck egg & 48 & & & & & & & & \\
\hline 20. Pork medium fat & 100 & & & & & & & & \\
\hline 21. Mustard greens & 30 & & & & & & & & \\
\hline 22. Glutinous rice & 120 & & & & & & & & \\
\hline 23. Vermicelli & 50 & & & & & & & & \\
\hline 24. Sugar apple & 150 & & & & & & & & \\
\hline 25. Cow milk & 200 & & & & & & & & \\
\hline 26. Milk powder & 10 & & & & & & & & \\
\hline 27. Chicken egg & 30 & & & & & & & & \\
\hline 28. Scad & 100 & & & & & & & & \\
\hline 29. Orange & 150 & & & & & & & & \\
\hline 30. Bread & 120 & & & & & & & & \\
\hline 31. Pork lean & 75 & & & & & & & & \\
\hline 32. Tamarind leaves & 20 & & & & & & & & \\
\hline 33. Pork leg & 75 & & & & & & & & \\
\hline 34. Chicken meat & 120 & & & & & & & & \\
\hline 35. Beef & 50 & & & & & & & & \\
\hline 36. Pork ribs & 40 & & & & & & & & \\
\hline
\end{tabular}

